\title{
In memoriam: Professor Chiaki Koizumi (1934-2016)
}

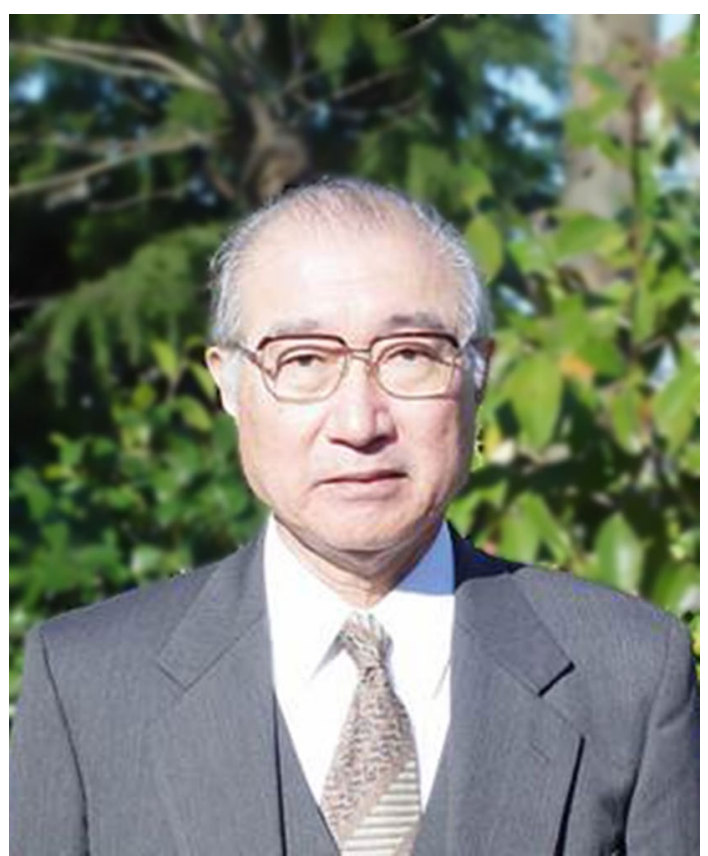

It is with great sadness that I report the passing of Professor Chiaki Koizumi (82) on December 31, 2016. Professor Koizumi formerly served as chairman of the Japanese Society of Fisheries Science, and was also an honorary member. He also formerly served as president of the Tokyo University of Fisheries, where he was professor emeritus.

Professor Koizumi graduated from the faculty of Fisheries Science at the Tokyo University of Fisheries in February 1957. After first serving as a probationary assistant, assistant professor and associate professor, he was appointed as full professor at the university in April 1979 and as the dean of students in April 1990. In November 1995, he became president of the university, and he continued to apply himself to education and research in fisheries science until his retirement at the end of his term of office in November 1999. In December of the same year, he was named professor emeritus of Tokyo University of Fisheries.

Professor Koizumi devoted immense effort over the course of many years to education and research in the field of food preservation and processing science, and his outstanding achievements included the publication of numerous research findings that led to both academic development in the field and the development of the Japanese fishing industry. In particular, in terms of education and research within the field of fisheries science, he was able to contribute to the development of the industry because he saw fisheries science as a practical science beyond the basic academic fields involving the preservation and processing of marine food products. His research findings were widely published, both domestically and abroad, in dozens of publications as well as in numerous academic journals. He also contributed to research in fields related to fisheries science.

His accomplishments were many and varied. For example, in the dried bonito stick called "Shirata," there occurs a deterioration in quality in which the surface first becomes grayish-white, and the discoloration then progresses deeper into the product. The product loses its luster and the stick becomes brittle. Professor Koizumi was the first to elucidate the process by which the fats in the bonito meat used as a raw material undergo auto-oxidation to form lipid peroxides, causing ruptures in the porphyrin rings of myoglobin in the muscle. Through a histochemical search, he was able to show that strong auto-oxidation occurred in the connections between the muscle fibers in the sections afflicted with "Shirata," due to a moistening of the subcutaneous fats. These findings led to quality control guidelines for fish raw material used in the production of dried bonito sticks. In recognition of this accomplishment, he received the Hen-mi Award in 1966 from the Japan Canners Association (Corp.). 
He was also the first to demonstrate that the phenomenon of "green meat," which occurs in well-steamed tuna meat, was due to a characteristic green pigment which possesses a heme structure that occurs as a result of anaerobically steaming myoglobin, trimethylamine oxide and cysteine. He showed that trimethylamine oxide content could be used to predict the appearance of "green meat" before steaming, which greatly contributed to raw material handling and production control in canning. In recognition of this achievement, he received an encouragement award in 1967 from the Japanese Society of Fisheries Science (Corp.).

In addition, he was the recipient of an achievement award from the Japanese Society of Fisheries Science in 1994 for his outstanding contributions to the development of the fishing industry by clarifying preservation conditions for each type of fish through detailed chemical analyses of changes in meat quality during processing and preservation as part of chemical research on the processing and preservation of marine products. At the same time, he worked diligently at managing the academic society. He served in a number of important posts including director in charge of general affairs and chairman of the academic journal editorial board from 1991, vice president beginning in 1994, and chairman of the executive committee for the Japanese Society of Fisheries Science's spring conference in 1995. In addition, he assumed important duties in the operation of the society as president for a period of two years beginning in April 1996.

Professor Koizumi also participated in the operation and management of the Tokyo University of Fisheries. He served successively as head of the Food Science and Technology Department, head of the attached laboratory and workshop, and director of the Health Supervision Center. He devoted much effort toward developing the university's education and research environment, and as the dean of the educational office, he focused on improving undergraduate student education and research and improving the benefits and welfare environment. In addition, after serving as president of the Tokyo University of Fisheries, he worked in his capacity as operational management leader to improve the university's educational and research environment.

Professor Koizumi saw fisheries science in Japan as a practical science, and sought to develop fisheries science education and research at the university. In addition, as a member of society, he served as a member of various academic and government-related committees, and was dedicated to the development of the fishing industry. In recognition of his meritorious deeds achieved through many years of steady effort, he received the Order of the Sacred Treasure, Gold Rays with Neck Ribbon, which was conferred in the spring of 2010 for his contribution in elucidating the mechanism by which marine food products deteriorate in quality and devising methods for prevention.

A great number of capable professionals have been trained and sent out into society under the influence of Professor Koizumi's character and his rich knowledge and experience. We intend to carry on his passion for education and research. I sincerely pray that his soul may rest in peace.

Toshiaki Ohshima

Professor, Tokyo University of Marine Science and Technology 